\title{
Determinants of use of supervised delivery care under Ghana's fee exemption policy for maternal healthcare: the case of the Central Region
}

Henrietta Asante-Sarpong ${ }^{1 *}$, Adobea Yaa Owusu', Sheela Saravanan², Ernest Appiah ${ }^{1}$ and Mumuni Abu ${ }^{3}$

\begin{abstract}
Background: Improving access to supervised and emergency obstetric care resources through fee reduction/exemption maternity care initiatives has been touted as one major strategy to avoiding preventable maternal deaths. Evaluations on the effect of Ghana's fee exemption policy for maternal healthcare have largely focused on how it has influenced health outcomes and patterns of use of supervised care with little attention to understanding the main factors influencing use. This study therefore sought to explore the main individual and health system factors influencing use of delivery care services under the policy initiative in the Central Region.
\end{abstract}

Methods: A cross-sectional study was conducted using 412 mothers with children aged less than one year in one largely rural and another largely urban districts in the Central Region of Ghana from September to December 2013. Data were collected using a questionnaire survey on the socio-demographic characteristics of mothers, their knowledge and use of care under the fee free policy. Chi-square and Binary Logistic Regression tests were used to evaluate the main determinants of delivery care use under the policy.

Results: Out of the 412 mothers interviewed, 268 (65\%) reported having delivered their most recent birth under the fee exemption policy even though awareness about the policy was almost universal 401 (97.3\%) among respondents. Utilization however differed for the two study districts. Respondents in the Cape Coast Metropolis (largely urban) used delivery service more (75.7 \%) than those in the largely rural Assin North Municipal area (54.4 \%). Binary logistic regression results identified maternal age, parity, religion, place of residence, awareness and knowledge about the fee exemption policy for maternal healthcare as significantly associated with the likelihood of delivery care use under the policy. The likelihood of using supervised delivery care under the policy was lower for mothers aged 20-29 compared to those in the age bracket of 40-49 (Odds ratio $(O R)=0.069, p=0.003$ ). For their index (last child), mothers who already had 1,2 or 3 births were more likely to deliver under the policy than those with five or more births.

Mothers living in urban areas were 3.79 times more likely to use delivery services under the policy than those living in rural areas $(\mathrm{OR}=3.793, p=0.000)$. The likelihood of using delivery services under the policy was higher for mothers who were aware and had full knowledge of the total benefit package of the policy $(O R=13.820$, $p=0.022$ and $\mathrm{OR}=2.985, p=0.001$ for awareness and full knowledge respectively).

(Continued on next page)

\footnotetext{
*Correspondence: h.asarpong@arhr.org.gh; boatemaa23@yahoo.com; myboatemaa23@gmail.com

IInstitute of Statistical Social and Economic Research, University of Ghana, P.O. Box LG 74, Legon, Accra, Ghana

Full list of author information is available at the end of the article
} 
(Continued from previous page)

Conclusions: Delivery service use under the free maternal healthcare policy is relatively low (65\%) when compared with nearly universal awareness (97.3\%) about the policy. Factors influencing delivery service use under the policy operate at both individual and policy implementation levels. Effective interventions to improve delivery service use under the policy should target the underlying individual and health policy implementation factors identified in the study.

Keywords: Maternal deaths, Supervised care, Fee exemption policy for maternity care, Maternal healthcare

\section{Background}

Maternal mortality is a major public health problem globally but most especially in sub-Saharan Africa [1]. In Ghana, maternal mortality continues to be pervasive and improvements have been rather slow. The country's Maternal Mortality Ratio (MMR) is estimated to be 350 per 100,000 live births [1]. Investments in supervised and emergency obstetric care resources have been noted as being critical to avoiding these deaths as most deaths, occur around delivery and are caused by haemorrhage [2].

Multiple challenges however confront women's quest to access supervised care. These challenges include poor or inadequate health infrastructure, limited or unavailable medical supplies [3], adherence to negative socio-cultural beliefs and practices about pregnancy and child birth [4] and bad or non-existent transportation infrastructure to the nearest health facilities [5]. Financial challenges to accessing care have been particularly highlighted as critical to the use of supervised care $[6,7]$.

To address the financial challenges to accessing supervised care at birth, several counties including Ghana have adopted innovative financing mechanisms to address financial challenges to seeking care. The mechanisms introduced include fee exemptions, cash assistance, voluntary service contributions and public-private partnerships [8].

Studies on the effect of these financing mechanisms in low-and middle-income countries have focused on demand for obstetric services and healthcare expenditures. Ir, Souk and Van Damme [9] assessed the effectiveness of a Voucher Scheme introduced by the Cambodian Government in 2007 to improve access to skilled attendance for poor women in three rural health districts. The authors noted that even though the scheme had strong potential for reducing financial barriers to accessing skilled care at birth, other interventions for improving the supply of sufficient quality maternity services was necessary for the scheme to achieve its full potential [9]. In Burkina Faso Ridde, Kouanda, Bado, Bado \& Haddad [10] assessed the effect of a national maternal healthcare subsidy policy on household spending on facility-based deliveries and found that the policy was very effective in reducing household costs for delivery care [10]. Ridde and Diarra [11] have also expressed the need for further attention to be given to sustainable financing mechanisms for the effective implementation of fee-exemption initiatives [11].
In 2003, the government of Ghana introduced a delivery fee exemption policy that exempts all pregnant women from paying for delivery care in public, mission and some private facilities. Otherwise known as the "free delivery policy", the policy exempts all pregnant women from paying for all normal deliveries and the management of all assisted deliveries including caesarean sections. Under the policy, women are also exempted from paying for the management of medical and surgical complications arising out of deliveries, including the repair of vesico-vaginal and recto-vaginal fistulae [12].

Similar to other studies that have been undertaken in low- and middle- income countries on maternal healthcare financing mechanisms, previous studies in Ghana have largely examined the delivery fee exemption policy in terms of how it has influenced utilisation patterns $[13,14]$ and healthcare expenditures [15]. Less attention has been given to understanding the driving factors influencing use within local contexts. This study therefore sought to explore the key individual and health policy implementation factors influencing use of delivery care services under Ghana's free delivery policy.

\section{Methods}

\section{Study setting}

The Central Region was selected for the study based on the following reasons: (i) the region was selected among the first four pilot regions in which the fee exemption policy for maternal deliveries was implemented in 2003. (ii) compared to the three other pilot regions (Northern, Upper East and Upper West), the Central Region has not witnessed improvements in skilled attendance rate particularly between 2008 and 2012 when services under the policy was administered through the NHIS. (iii) Contrastingly the region also has a Maternal Mortality Ratio of 520/100,000 live births [16] a ratio which is far higher than the national average of 350/100,000 live births [1].

Two districts (Cape Coast Metropolitan Area and Assin North Municipal Area) in the Central Region were purposively selected from the seventeen districts of the region for the study. The two districts compared to the others have the highest maternal mortality ratios [17]. Cape Coast Metro is also largely urban whereas Assin North is largely rural [16] a scenario that provides an opportunity 
to assess differences in care received under the policy within rural and urban settings.

\section{Study participants}

The primary study population was mothers of reproductive age (15-49 years) with children under one year of age. The choice of women with these characteristics was based on the study goal that aims to examine factors influencing delivery service use under the 'free maternal healthcare' policy. The target population largely serves as the potential users and benefactors of services under the policy. Secondly, mothers whose most recent birth occurred 12 months prior to the survey are most likely to recall and give a better account of their experiences.

A total of 412 mothers were selected from the study districts (Cape Coast, $n=206$; Assin North, $n=206$ ) using a combined multi-staged, stratified and simple random sampling techniques. The sample size was determined with recourse to Kish [18] since the population under study was homogeneous and the total population of mothers with at least a child under one is not known [18]. The study participants were selected from eight different localities (4 rural and 4 urban) identified from a list of all rural and urban localities in the study areas through a simple random approach. The calculated sample populations for rural and urban areas from the total sample was shared equally across the study localities as the study population was homogeneous and therefore likely to share similar views and experiences.

This was followed by the identification of households in each locality from which women were interviewed. The identification of households began with a surveillance exercise that was undertaken by the research assistants through the help of local opinion leaders and healthcare volunteers in the respective localities. Having identified households in which mothers eligible for the interviews reside, a list/ sampling frame of these mothers was produced for each locality. From the sampling frame of mothers produced for each locality, a simple random approach (writing the names of each eligible respondent on pieces of papers, shaking them arbitrarily and selecting required number from the whole) was later employed to select the total number of respondents earmarked for each settlement or locality.

\section{Data generation}

Data were collected through the administration of a standardized questionnaire. The data collection exercise was undertaken concurrently in the two study districts between the months of September to December 2013. The questionnaire was administered to all 412 mothers and consisted of sections that asked questions related to their background characteristics such as age, marital status, education, religion and ethnicity, place of residence, employment status and parity.

Similar questions were asked for the background information of their spouses/partners. The other sections had questions related to their obstetric history, their knowledge and perceived need of services provided under the free delivery policy; and experiences with use of delivery care under the delivery fee exemption policy.

\section{Study variables}

The dependent variable is use of delivery services under the fee exemption policy. It was derived from the question, "Did you deliver for free under the 'free delivery policy' or you paid for delivery services?" The dependent variable was measured by using the labels 1 and 2 with 1 being 'Delivery for free' and 2, 'Delivery not for free.

The independent variables were selected with reference to what has been used in previous studies. They comprised of those related to the socio-demographic characteristics of women as well as their partners and others on the free delivery policy. The variables selected on the socio-demographic characteristics of women and their husbands/partners included age, religion, level of education, employment status, marital status, parity, place of residence and ethnicity. The variables were defined and measured as follows.

Education was defined as completed educational status and was ranked from 1 to 5 with label 1 for No formal education, 2 for primary education, 3 for Middle/Junior High School (JHS), 4 for Secondary/Senior High School (SHS)/Technical education, 5 for higher than secondary. Employment status was defined as the category of work respondents were engaged in and was ranked from 1 to 5 with 1 for 'unemployed, 2 (Self-employed), 3 (Paid employee), 4 (Paid informal worker) and 5 (Other forms of employment mostly seasonal employment). Parity referred to the total number of live births a woman had and was ranked from 1 to 5 with 1 for parity one, 2 for parity two, 3 for parity three, 4 for parity 4 and 5 for parity five and above. Place of residence was ranked 1 and 2 with 1 being Urban and 2, Rural. The marital status of respondents was ranked into three categories. Those who were currently married or cohabiting were assigned rank 1 , formerly married, rank 2 and single, never married women given rank 3 .

The variables for the free delivery policy were awareness about the 'free delivery' policy and knowledge about benefit package for the 'free delivery' policy. Awareness of the free delivery policy was defined as having heard about the existence of the policy and ranked 1 for a 'Yes' and 2 for a 'No'. Knowledge about the policy was also ranked as 1 and 2 with 1 referring to answering yes to having knowledge about the full benefit package of the policy and 2 for answering no to having knowledge about the policy. 


\section{Statistical analysis}

The Statistical Package for the Social Sciences (SPSS) software version 20.0 was used to analyze the quantitative data. Descriptive statistics were used for frequency counts and percentage distribution of background characteristics of respondents as well as prevalence of use of delivery services under the free maternal healthcare policy. The Chi-Square test was used to test for the statistical associations between use of delivery care and other independent variables. The binary-logistic regression model was used for identifying the main determinants of use of delivery care under the fee exemption policy.

Three models containing variables of interest were fitted for the outcome variable (use of delivery care). The first model contained variables on the socio-demographic characteristics of mothers. This model was used to assess the association between their socio-demographic characteristics and use of delivery services. The second model contained variables on the demographic characteristics of the selected mothers and that of their husbands/partners. This helped to assess whether the husband's/partner's characteristics influenced the association between the background characteristics of the woman and the outcome variable. A third model containing variables on the sociodemographic characteristics of the woman as well as that of their husbands/partners and the free delivery policy was also estimated. The final model (Model 3) was used to estimate whether health policy and husbands'/partners' socio- demographic characteristic factors moderate the association between mothers' socio-demographic characteristics and delivery care use.

\section{Results}

\section{Socio-demographic characteristics of respondents}

Information collected on the socio-demographic characteristics of mothers interviewed included their age, level of education, marital status, parity, employment status, place of residence, religion and ethnicity. As shown in Table 1, majority of the mothers were within the age bracket of $20-29$ years (58 \%) with only $4.4 \%$ in the age bracket of $40-49$ years. A significant proportion of the respondents were married or cohabiting (87.7\%), had had some level of education (85.4\%) with those with Middle/JHS level education in the majority (39.6\%). Only $2.4 \%$ had received tertiary level education.

In terms of ethnicity, $78.4 \%$ of the total respondents were Akans with majority from the Fante ethnic group. The other Akan ethnic groups mentioned were Asante, Akyem and Bono. This finding was not surprising as most residents of the Central Region belong to the Fante ethnic group. Ewes were the second largest ethnic group (16\%) with mothers from other ethnic groups mostly of northern Ghana decent (Nanumba, Dagomba and Hausa) forming $3.9 \%$ of the sample. The mothers were mostly Christians
(83.6 \%) with the majority (35.7 \%) affiliated to Pentecostal or Charismatic churches as is the trend nationally. A greater proportion of the respondents were self-employed (58 \%) and engaged mostly in trading activities with only $5.8 \%$ engaged in formal employment. A little over half of the mothers $(58.5 \%)$ resided in urban areas with $41.5 \%$ residing in rural localities which also reflect the national trend of increasing urban residence in Ghana. The proportion of Ghanaians living in urban areas has increased from $43.8 \%$ in the year 2000 to $50.9 \%$ in 2010 [16].

\section{Determinants of delivery service use}

Three binary logistic regression models were used to identify the determinants of delivery care use under the fee exemption policy. Chi-square tests were also used to assess the statistical associations between utilization and selected independent variables. More than half (65\%) of mothers interviewed delivered their most recent birth with the policy. Comparing the two districts, utilization of delivery services was rather low for the Assin North Municipal Area 54.4 \% $(n=112)$ compared with $75.7 \%$ ( $n=156)$ in Cape Coast Metropolis).

From the Chi-square test results, religion (0.000), place of residence (rural/urban) (0.000), parity (0.003) and marital status $(0.010)$ had a statistically significant association with delivery care use. Comparing the two districts, the variables that had a statistically significant relationship with utilization of delivery services in the Cape Coast Metropolis were education, marital Status, religion and parity. Religion and place of residence were significantly related to the use of delivery services in the Assin North municipal area. Maternal age, education, employment status, place of delivery and attendant at delivery did not have a statistically significant relationship with utilization of delivery care.

The results of the three binary logistic regression models are presented in Table 2. Model 1 which contains variables on the socio-demographic characteristics of the woman confirmed parity, religion, marital status and place of residence as significantly related to delivery care use under the free maternal healthcare policy.

In model 1 , at $p \leq 0.05$, mothers aged $20-29$ and 30-39 were 0.178 and 0.421 respectively less likely to use delivery services than those aged 40-49. The likelihood of using delivery care under the policy was lower for mothers who were married or co-habiting and mothers who were either widowed, divorced/separated compared to those who were single. Mothers who resided in urban areas were 3.57 times more likely to use delivery services under the policy than those in rural areas. Mothers with 1, 2 and 3 births had higher odds of delivering with the policy than those with five or more births. Orthodox Christians and other Christians of the Seventh Day Adventist (SDA) group and Jehovah's Witnesses were less likely to deliver 
Table 1 Percentage distribution of background characteristics of respondents

\begin{tabular}{|c|c|c|c|c|c|}
\hline Background Characteristics & Frequency & Percent & Parity & & \\
\hline Age Group & & & 1 & 125 & 30.3 \\
\hline $20-29$ & 239 & 58.0 & 2 & 109 & 26.5 \\
\hline $30-39$ & 155 & 37.6 & 3 & 65 & 15.8 \\
\hline $40-49$ & 18 & 4.4 & 4 & 35 & 8.5 \\
\hline Total & 412 & 100 & 5 and above & 78 & 18.9 \\
\hline Highest level of education & & & Total & 412 & 100.0 \\
\hline
\end{tabular}

$\begin{array}{lll}\text { Pre-school } & 22 & 5.3 \\ \text { Primary } & 108 & 26.2 \\ \text { Middle/JSS/JHS } & 163 & 39.6 \\ \text { Secondary/SSS/SHS/Tech/Voc } & 49 & 11.9 \\ \text { Higher than secondary } & 10 & 2.4 \\ \text { Don't know } & 6 & 1.5 \\ \text { No education } & 54 & 13.1 \\ \text { Total } & 412 & 100.0\end{array}$

Marital status

$\begin{array}{lll}\text { Married or cohabiting } & 355 & 87.7 \\ \text { Divorced/separated } & 14 & 3.5 \\ \text { Widowed } & 2 & 0.5 \\ \text { Never married/never cohabited } & 34 & 8.4 \\ \text { Total } & 405 & 100\end{array}$

Religious affiliation

Catholic 42

Anglican

Methodist

Presbyterian

Pentecostal/charismatics

Other Christian

Moslem

Traditional

Spiritualist

No religion

Other

Total

Employment status

Unpaid family worker/farmer

Unemployed

Self-employed

Employee - formal work (paid)

Informal work (paid)

Others

Total
Table 1 Percentage distribution of background characteristics of respondents (Continued)

with the policy compared to Muslims. The relationship between mother's education, ethnicity and employment status and delivery care use was not significant statistically.

Model 2 contained variables on the socio-demographic characteristics of mothers as well as that of their partners. In model 2, all the background characteristics of mothers identified as predictors of delivery service use in model 1 still remained statistically significant except for the marital status of the mother. The variables on husbands'/partners' characteristics introduced (age, education and employment status) were not statistically significant predictors of delivery service use. The introduction of the husbands'/ partners' variables was however important as it helped to increase the adjusted coefficient of determination $\left(\mathrm{R}^{2}\right)$ from (0.302) in model 1 to (0.380).

Model 3 contained variables on the socio-demographic characteristics of the woman and that of the husband or partner as well as variables on the free delivery policy. The results identified religion, parity, place of residence and maternal age as statistically significant predictors of delivery service use. In addition, awareness and full knowledge about the free maternal healthcare policy were also found to be statistically significant predictors of delivery service use. Maternal education, ethnicity and employment status were not observed as statistically significant predictors of delivery service use under the policy.

The odds of delivering with the policy was 2.985 times higher for mothers who had full knowledge about the policy relative to those who did not have full knowledge about the policy. Similarly, mothers who were aware of the existence of the free maternal healthcare policy were 13.820 times more likely to have delivery services under the policy than those who were not aware of the policy.

The likelihood of using delivery care under the policy was lower for mothers aged 20-29 compared to those in the age bracket of $40-49$ (Odds ratio $(O R)=0.069$, $p=0.003)$. Mothers who already had 1, 2 or 3 children were more likely to deliver their index child under the policy than those with five or more births. Mothers living in urban areas were 3.793 times more likely to use delivery services under the policy than those living in rural areas $(\mathrm{OR}=3.793, p=0.000)$. 
Table 2 Binary logistic regression results of predictors of delivery care use using individual, husband/partner and health policy factors

\begin{tabular}{|c|c|c|c|}
\hline \multirow[t]{2}{*}{ Variable } & $\begin{array}{l}\text { Model } 1 \text { Individual } \\
\text { variables }\end{array}$ & \multirow{2}{*}{$\begin{array}{l}\text { Model } 2 \text { Individual/ } \\
\text { Partner variables } \\
\text { Odds Ratio }\end{array}$} & \multirow{2}{*}{$\begin{array}{l}\text { Model } 3 \text { Individual/Partner/ } \\
\text { Health Policy variables } \\
\text { Odds Ratio }\end{array}$} \\
\hline & Odds Ratio & & \\
\hline \multicolumn{4}{|l|}{ Age Group $(\mathrm{RC}=40-49)$} \\
\hline $20-29$ & 0.178 & $0.088^{* *}$ & $0.069^{* *}$ \\
\hline $30-39$ & 0.421 & 0.271 & 0.247 \\
\hline \multicolumn{4}{|l|}{ Parity ( $\mathrm{RC}=5$ and above) } \\
\hline 1 & $3.405^{* *}$ & $4.998^{* *}$ & $5.283^{* *}$ \\
\hline 2 & $3.974^{* * *}$ & $5.338^{* *}$ & $6.390^{* * *}$ \\
\hline 3 & $4.171^{* *}$ & $4.675^{* *}$ & $5.713^{* *}$ \\
\hline 4 & 2.146 & 3.248 & 3.087 \\
\hline \multicolumn{4}{|l|}{ Religion ( $\mathrm{RC}=$ Muslim) } \\
\hline Christian (Catholic) & 0.719 & 0.584 & 0.527 \\
\hline Christian (Orthodox) & $0.146^{* * *}$ & $0.110^{* * *}$ & $0.077^{* * *}$ \\
\hline Other Christian (SDA, Jehovah's Witnesses) & $0.344^{*}$ & 0.305 & 0.283 \\
\hline Christian (Pentecostal/Charismatic) & 0.581 & 0.751 & 0.847 \\
\hline Other (Traditional/Spiritual/No religion) & 0.299 & 0.613 & 0.636 \\
\hline \multicolumn{4}{|l|}{ Education ( $\mathrm{RC}=$ Other - Vocational, Technical) } \\
\hline No Education & 1.019 & 0.788 & 0.968 \\
\hline Primary & 1.006 & 0.450 & 0.427 \\
\hline Middle/JHS & 1.771 & 1.214 & 1.141 \\
\hline Secondary/SHS/Technical & 2.403 & 2.343 & 2.634 \\
\hline Higher than Secondary & 3.226 & 0.263 & 0.217 \\
\hline \multicolumn{4}{|l|}{ Ethnicity (RC = Other (Ga-Adangme, Guan, Hausa)) } \\
\hline Akan & 1.531 & 2.873 & 2.905 \\
\hline Ewe & 2.049 & 3.151 & 2.724 \\
\hline \multicolumn{4}{|c|}{ Marital Status ( $\mathrm{RC}=$ Single (Never married, Never-cohabited) } \\
\hline Married/cohabiting & $0.316^{*}$ & 0.124 & 0.094 \\
\hline Formerly in union (Widowed, Divorced/Sep) & $0.114^{* *}$ & 0.178 & 0.098 \\
\hline \multicolumn{4}{|l|}{ Residence $(\mathrm{RC}=$ Rural) } \\
\hline Urban & $3.566^{* * *}$ & $3.188^{* * *}$ & $3.793^{* * *}$ \\
\hline \multicolumn{4}{|l|}{ Employment Status (RC = Other - seasonal work) } \\
\hline Unemployed & 2.151 & 2.969 & 4.714 \\
\hline Self-employed & 1.416 & 1.448 & 1.809 \\
\hline Employee (Paid) & 0.994 & 4.691 & 13.629 \\
\hline Informal work (paid) & 2.896 & 3.891 & 4.673 \\
\hline \multicolumn{4}{|c|}{ Husband/Partner Education (RC = Other- Vocational, Technical) } \\
\hline No education & & 0.791 & 0.652 \\
\hline Primary & & 4.297 & 5.177 \\
\hline Middle/JHS & & 4.740 & 6.222 \\
\hline Secondary/SHS/Technical & & 2.336 & 2.925 \\
\hline Higher than Secondary & & 7.573 & 8.317 \\
\hline \multicolumn{4}{|c|}{ Husband Employment Status ( $\mathrm{RC}=$ Other - seasonal work) } \\
\hline Unpaid Family worker & & 1.317 & 1.227 \\
\hline Unemployed & & 3.075 & 3.150 \\
\hline
\end{tabular}


Table 2 Binary logistic regression results of predictors of delivery care use using individual, husband/partner and health policy factors (Continued)

\begin{tabular}{|c|c|c|c|}
\hline Self-employed & & 1.889 & 1.784 \\
\hline Employee (Formal work paid) & & 3.654 & 6.386 \\
\hline Informal work (paid) & & 3.096 & 3.320 \\
\hline Age of husband & & 1.024 & 1.022 \\
\hline \multicolumn{4}{|l|}{ Awareness about policy $(\mathrm{RC}=\mathrm{No})$} \\
\hline Awareness about policy (Yes) & & & $13.820^{*}$ \\
\hline \multicolumn{4}{|c|}{ Full knowledge about policy $(\mathrm{RC}=\mathrm{No})$} \\
\hline Full Knowledge (Yes) & & & $2.985^{* * *}$ \\
\hline Constant & 2.723 & 0.532 & 0.020 \\
\hline Nagelkerke $\mathrm{R}^{2}$ & 0.302 & 0.380 & 0.433 \\
\hline
\end{tabular}

Note: For significance levels

$R C$ reference category

${ }^{*} p<0.05 ;{ }^{* *} p<0.01 ;{ }^{* * *} p<0.001$

The introduction of variables on the fee exemption policy (awareness and full knowledge of the free delivery's benefit package) was relevant as those variables were also significant in explaining delivery care use under the policy. Additionally, model 3 was an improvement over models 1 and 2 as the adjusted coefficient of determination $\left(R^{2}\right)$ increased further to close to $45 \%$ (0.433) compared to 0.302 for model 1 and 0.380 for model 2 .

\section{Discussion}

In this study we found that over two-thirds of mothers who participated in the study used supervised delivery services under the fee exemption policy for maternal healthcare for their most recent birth. Utilization was however lower for mothers in the largely rural district than those from urban districts. A little over 7 out of 10 mothers in urban areas delivered for free under the policy compared to approximately 5 in 10 for mothers in rural areas. The findings is in line with an earlier study that has confirmed a possibility of marked variations in utilization of maternal healthcare services under given healthcare financing mechanism due to challenges in the design and/ or implementation of the policy or initiative [19].

The study also found the major determinants of delivery care use under the policy as, age, religion, marital status, parity, place of residence, awareness and knowledge about the fee exemption policy.

The likelihood of using delivery care under the policy was lower for younger mothers aged 20-29 compared to older mothers in the age bracket of 40-49. The finding is inconsistent with previous studies [20] and at the same time consistent with others $[21,22]$. The relatively lower use of the free delivery services by younger mothers could be partly attributed to concerns of the quality of maternity care received under the policy. The Central region has been particularly noted as one region with a very low uptake of care provided under the National Health Insurance
Scheme (NHIS) which includes free maternity care and lack of confidence in the programme has been noted as one major reason [23]. Younger mothers who most likely will be having their first births will most likely be very enthusiastic about receiving the most efficient care and may therefore choose to pay for maternity services which many consider to be of a better quality than services provided for free. Older mothers particularly those who already have many children on the other hand may have varied expenditures to deal with and would therefore not prefer to add that of an additional birth if they can receive care at no cost.

The study also found that mothers with lower parity had higher odds of delivering with the policy than those with higher parity. Previous studies have also confirmed a strong association between lower parity and use of maternal healthcare services $[22,24]$. Within the study setting usage of free care was lower for mothers with higher parities relative to those with lower parities partly because ordinarily, women with many children have been exposed to a number of childbearing episodes and therefore will not be too enthusiastic and religious to seek for supervised care even when it comes at no cost.

On religion, the results showed that orthodox Christians and other Christian religious groups as the Seventh Day Adventists (SDA) and Jehovah's Witnesses had a lower likelihood of delivering with the policy than Muslim women. There was no significant relationship between supervised care use under the policy and religion among mothers who were Traditionalist/Spiritualist. The finding on religion may suggest differences in religious ideologies in seeking for supervised/facility-based services during pregnancy and childbirth among different religious groups. Previous studies [21, 25, 26] have confirmed a strong association between religion and health-seeking behaviours during pregnancy, delivery and the post-partum period. 
Place of residence has been found to constitute a major determinant of healthcare use as it shapes individual opportunities and exposure to healthcare resources $[22,27]$. It is therefore not surprising that place of residence was highly significant in predicting delivery care use under the policy. Similar to what has been reported in earlier studies [22, 27, 28], mothers residing in rural areas were 3.79 times less likely to use delivery services under the free delivery policy than those living in urban areas. These studies have shown that urban settlements in Ghana and other developing economies receive a better share of healthcare resources including supervised maternity services. Additionally, well-known communitylevel barriers including poor transportation networks and distance to available healthcare facilities could partly explain variations in access to services between women in rural and urban areas [20].

Most rural communities are disadvantaged when it comes to the distribution of health infrastructure, human and medical resources and the availability of transportation infrastructure to the nearest health facility. The findings suggest the need for increased attention to improving healthcare resources in rural areas to ensure that resources are equitably distributed across rural and urban areas. Mothers will be willing and happy with using supervised care during pregnancy and childbirth if a good facility is available and accessible to them.

The study also introduced variables on health policy in the regression analysis as it has become imperative to look beyond individual- and community-level factors in addressing challenges to accessing supervised care at birth. Addressing challenges associated with accessing care under a given healthcare policy is largely beyond the remit of the individual woman. The variables introduced (awareness and knowledge about the fee exemption policy) were statistically significant in explaining delivery care use under the policy.

Some of the findings of the study were not consistent with certain hypotheses explaining maternal healthcare service use. For instance maternal education which has often been identified as a catalyst to empowering women and exposing them to better use of healthcare services $[20,24,27]$ was not statistically associated with delivery care use in the study setting. This could be attributed to the general low level of education of most indigenous inhabitants of the Central region. The region has been classified among the poorest regions in Ghana with majority of its inhabitants not highly educated [23]. Education could therefore not be critical in influencing women's delivery decisions in this study.

The study acknowledges some limitations which should be considered in the interpretation of the results. First, even though the study was undertaken in a pilot region in which the fee exemption policy was implemented, the findings cannot be generalized for the entire region since only 2 districts out of the nineteen (19) existing districts were selected. Secondly, the findings can best inform decisions regarding effective implementation of the delivery fee exemption policy at only the micro level. Furthermore, the study was cross-sectional and employed the use of a structured questionnaire to collect primary data. Information collected from the questionnaire survey was largely reliable in answering the study's objective of identifying factors that influences women's use of supervised care at birth. A questionnaire survey is however limited in so far as it does not allow for probing to understand further and provide meanings to the study's findings. Even though useful, the present study was not intended to provide qualitative insights into how the factors identified influence women's use of supervised delivery care under the policy.

\section{Conclusions}

The study identified place of residence (rural/urban) as one of the strongest determinants of supervised care use under the free maternal healthcare policy with mothers residing in rural areas less likely to use the services than those in urban areas. The results on place of residence have very useful implications for effective implementation of the free delivery policy with regards to improving equitable access to care for both rural and urban inhabitants. The finding suggests that efforts at improving access to supervised care under the "free delivery" policy should not only target disadvantaged individuals but also disadvantaged localities in which many poor and disadvantaged women live.

Additionally individual and policy level factors affecting delivery service use such as maternal age, parity, marital status, awareness and knowledge about the free delivery policy have been identified in the study. Service improvement interventions that take cognisance of these factors are likely to have an impact on utilisation of supervised care under the delivery fee exemption policy.

Overall, the findings of this study have policy implications for addressing some unfinished business of Millennium Development Goal (MDG) 5 on improving maternal health under the Sustainable Development Goals (SDGs). In particular, the findings from this study provide useful lessons for realizing targets for improving maternal and child health (targets 3.1, 3.2 and 3.8) under SDG 3 which seeks to ensure healthy lives and promotes well-being for all at all ages. A realistic and achievable inter-sectorial intervention programmes aimed at addressing both individual and policy implementation bottlenecks should be put in place to improve maternal health during the post MDG period especially for rural localities. 


\section{Abbreviations}

ADDRF, African Doctoral Dissertation Research Fellowship; APHRC, African Population and Health Research Centre; DAAD, Deutscher Akademischer Austausch Dienst/German Academic Exchange Service; DHMT, District Health Management Team; IDRC, International Development Research Centre; IRB, Institutional Review Board; ISSER, Institute of Statistical Social and Economic Research; MDG, Millennium Development Goal; NHIS, National Health Insurance Scheme; NMIMR, Noguchi Memorial Institute for Medical Research; SDA, Seventh Day Adventist; SDGs, Sustainable Development Goals; SPSS, Statistical Package for the Social Sciences

\section{Acknowledgements}

The research received financial support from the German Academic Exchange Service (DAAD) through the PhD in Development Studies programme offered by the Institute of Statistical Social and Economic Research, University of Ghana. The research was also partially funded by an African Doctoral Dissertation Research Fellowship award offered by the African Population and Health Research Center (APHRC) in partnership with the International Development Research Centre (IDRC).

The authors are also grateful to Barbara English, Master Editor at Wordsmiths English Consultancy for reviewing and providing useful inputs into the initial draft of the manuscript.

\section{Funding}

The data collection and management for this study was funded by the Deutscher Akademischer Austausch Dienst (DAAD)/German Academic Exchange Service and an African Doctoral Dissertation Research Fellowship (ADDRF) award received by the lead author. The ADDRF award was offered by the African Population and Health Research Center in partnership with the International Development Research Centre (IDRC). The data analysis and write-up did not receive any financial support.

\section{Availability of data and materials}

The data supporting the findings and conclusions of this study are available at the primary author's institution, Institute of Statistical Social and Economic Research (ISSER) of the University of Ghana. They can be made available upon request to the primary author at the contact addresses provided in this paper.

\section{Authors' contributions}

HAS is the principal author and was involved in developing the research concept, conception of the methodology, data collection, data analysis, interpretation of results and writing of manuscript. AYO contributed to developing the research concept, the conception of the methodology, interpretation of the results and review of manuscript. SS supported in developing the research concept, conception of the research methodology and review of manuscript. EA contributed to the research concept, review of data collection instruments, supervision of data collection and review of manuscript. MA participated in the conception of the methodology, supervised the statistical analysis and edited the manuscript. All authors read and approved the final manuscript.

\section{Authors' information}

HAS is a Doctoral Fellow of the Institute of Statistical Social and Economic Research (ISSER), University of Ghana (UG). AYO is a Senior Research Fellow, ISSER, UG. SS is a Senior Researcher, South Asia Institute. EA is Research Fellow, ISSER. MA is a lecturer at the Regional Institute for Population Studies, UG.

\section{Competing interests}

The authors declare that they have no competing interests.

\section{Consent for publication}

The study participants were informed that the information they will provide was strictly for academic purposes (thesis and publication). In this regard their permission was sought in quoting or using any aspects of the information given in any publications that may result from this research.

\section{Ethics approval and consent to participate}

Ethical clearance for undertaking the study was sought from the Institutional Review Board (IRB) of the Noguchi Memorial Institute for Medical Research,
University of Ghana. The study protocol and respondent consent forms were reviewed, and approved by the board with an ethical approval code NMIMR-IRB CPN 113/12-13.

The Central Regional Directorate of the Ghana Health Service and the District Health Management Teams (DHMT) offices of the selected districts as well as the local government authorities in the respective districts were also consulted for approval before the commencement of data collection exercise. Participants for the interviews were provided with all the relevant study information to assess their willingness to participate in the study. They were informed that the information to be collected was strictly for academic purposes (thesis and publications) and their participation was voluntary. The study participants were therefore interviewed only after they had agreed to do so. Respondents who agreed to participate in the study were requested to sign or thumb-print a consent form.

\section{Author details}

${ }^{1}$ Institute of Statistical Social and Economic Research, University of Ghana, P.O. Box LG 74, Legon, Accra, Ghana. ${ }^{2}$ South Asia Institute, Im Neuenheimer Feld 330, 69120 Heidelberg, Germany. ${ }^{3}$ Regional Institute for Population Studies, University of Ghana, P.O. Box LG 96, Legon, Accra, Ghana.

Received: 17 October 2015 Accepted: 12 July 2016 Published online: 19 July 2016

\section{References}

1. Chou D, Inoue M, Mathers C, Oestergaard M, Say, Mills S, Suzuki E, Wilmoth J. Trends in maternal mortality: 1990 to 2008. Estimates developed by WHO UNICEF UNFPA and The World Bank. Geneva: World Health Organization; 2010.

2. Campbell OMR, Graham WJ. Strategies for reducing maternal mortality: getting on with what works. Lancet. 2006;368(9543):1284-99.

3. Cham M, Sundby J, Vangen S. Availability and quality of emergency obstetric care in Gambia's main referral hospital: women-users' testimonies. Reprod Health. 2009;6(1):5-12.

4. Kyomuhendo GB. Low use of rural maternity services in Uganda: impact of women's status, traditional beliefs and limited resources. Reprod Health Matters. 2003;11(21):16-26.

5. Wagle R, Sabroe S, Nielsen B. Socioeconomic and physical distance to the maternity hospital as predictors for place of delivery: an observation study from Nepal. BMC Pregnancy Childbirth. 2004;4(1):8-17.

6. Bazzano AN, Kirkwood B, Tawiah-Agyemang C, Owusu-Agyei S, Adongo P. Social costs of skilled attendance at birth in rural Ghana. Int J Gynecol Obstet. 2008;102(1):91-4

7. Levin A, Dmytraczenko T, McEuen M, Ssengooba F, Mangani R, Van Dyck G. Costs of maternal health care services in three anglophone African countries. Int J Health Plann Manage. 2003;18(1):3-22.

8. Devadasan N, Elias MA, John D, Grahacharya S, Ralte L. A conditional cash assistance programme for promoting institutional deliveries among the poor in India: process evaluation results. In: Fabienne R, Sophie W, Vincent D, editors. Reducing financial barriers to obstetric care in low-income countries. Antwerp: Studies in health services organisation and policy; 2008. p. 167-98.

9. Ir DH, Souk N, Van Damme W. Using targeted vouchers and health equity funds to improve access to skilled birth attendants for poor women: a case study in three rural health districts in Cambodia. BMC Pregnancy Childbirth. 2010;10(1):1-11.

10. Ridde V, Kouanda S, Bado A, Bado N, Haddad S. Reducing the medical cost of deliveries in Burkina Faso is good for everyone, including the poor. Plos One. 2012;3(7):1-8.

11. Ridde V, Diarra A. A process evaluation of user fees abolition for pregnant women and children under five years in two districts in Niger (West Africa). BMC Health Serv Res. 2009;9(1):89-104.

12. Ofori-Adjei D. Ghana's free delivery care policy. Ghana Med J. 2007;41(3):94-5.

13. Ansong-Tornui J, Armar-Klemesu M, Arhinful D, Penfold S, Hussein J. Hospital based maternity care in Ghana-findings of a confidential enquiry into maternal deaths. Ghana Med J. 2007;3(41):125-32.

14. Witter S, Adjei S, Armar-Klemesu M, Graham W. Providing free maternal health care: ten lessons from an evaluation of the national delivery exemption policy in Ghana. Glob Health Action. 2009;2:1-5.

15. Asante FA, Chikwama C, Daniels A, Armar-Klemesu M. Evaluating the economic outcomes of the policy of fee exemption for maternal delivery care in Ghana. Ghana Med J. 2007;3(41):110-7. 
16. Ghana Statistical Service. 2010 Population and housing census: Summary report of final results. Accra: Ghana Statistical Service; 2012.

17. Ghana Health Service. Central regional annual report 2012. Accra: Ghana Health Service; 2013

18. Kish L. Survey sampling. New York: Wiley-Interscience; 1965.

19. Powell-Jackson T, Morrison J, Tiwari S, Neupane B, Costello A. The experiences of districts in implementing a national incentive programme to promote safe delivery in Nepal. BMC Health Serv Res. 2009;9(1):97-107.

20. Ononokpono DN, Odimegwu CO, Imasiku EN, Adedini SA. Does it really matter where women live? A multilevel analysis of the determinants of postnatal care in Nigeria. Matern Child Health J. 2013;17 Suppl 1:1-10.

21. Doku D, Neupane S, Doku PN. Factors associated with reproductive health care utilization among Ghanaian women. BMC Int Health Hum Rights. 2012; 12:29-36.

22. Gabrysch S, Campbell OMR. Still too far to walk: Literature review of the determinants of delivery service use. BMC Pregnancy Childbirth. 2009;9(1): 34-51.

23. Ghana Statistical Service Ghana Living Standards Survey. Report of the Fifth Round (GLSS 5). Accra: GSS; 2008.

24. Overbosch G, Nsowah-Nuamah N, Van Den Boom G, Damnyag L. Determinants of antenatal care use in Ghana. J Afr Econ. 2004;13(2):277-301.

25. Gyimah SO, Takyi BK, Addai I. Challenges to the reproductive-health needs of African women: on religion and maternal health utilization in Ghana. Soc Sci Med. 2006;62(12):2930-44.

26. Hazarika I. Factors that determine the use of skilled care during delivery in India: implications for achievement of MDG-5 targets. Matern Child Health J. 2010;15(8):1381-8.

27. Fotso JC, Ezeh A, Oronje R. Provision and use of maternal health services among urban poor women in Kenya: what do we know and what can we do? J Urban Health. 2008;85(3):428-42.

28. Gething PW, Amoako Johnson F, Frempong-Ainguah F, Nyarko P, Baschieri A, Aboagye P, Falkingham J, Matthews Z, Atkinson PM. Geographical access to care at birth in Ghana: a barrier to safe motherhood. In: Economic and social research council. Centre for Population change working paper 2012. Number 21

\section{Submit your next manuscript to BioMed Central and we will help you at every step:}

- We accept pre-submission inquiries

- Our selector tool helps you to find the most relevant journal

- We provide round the clock customer support

- Convenient online submission

- Thorough peer review

- Inclusion in PubMed and all major indexing services

- Maximum visibility for your research

Submit your manuscript at www.biomedcentral.com/submit
Biomed Central 